\title{
Comunicação entre líderes e liderados: visão dos enfermeiros
}

\author{
COMMUNICATON BETWEEM LEADERS AND SUBORDINATES:NURSE'S VISION
}

COMUNICACION ENTRE LIDERES Y LIDERADOS:VISION DE LOS ENFERMEROS

\author{
Katia Massuda Alves Batista dos Santos ${ }^{1}$, Maria Júlia Paes da Silva ${ }^{2}$
}

\begin{abstract}
RESUMO
O trabalho procurou verificar como os enfermeiros percebem o processo de comunicação entre eles e os seus superiores. O estudo, do tipo descritivo, exploratório, correlacional, com abordagem quantitativa, foi levado a efeito em uma amostra com 42 enfermeiros de um hospital privado, beneficente de porte médio da cidade de São Paulo, tendo os dados sido colhidos no periodo de 28/02 a 02/03 de 2002. Os resultados indicam que há algumas falhas na comunicação dos lideres que provavelmente está causando impacto negativo em seus liderados. Lacunas que alertam para a necessidade dos lideres realizarem um esforço para reavaliar o processo de comunicação e para compreender o que não é dito verbalmente pelos liderados para que a liderança seja efetiva e os objetivos da organização concretizados.
\end{abstract}

PALAVRAS-CHAVE Comunicação. Liderança. Relacões interpessoais.

\section{ABSTRACT}

The work tried to verify the nurse's point of view of their communication process with their superiors. This is a descriptive, exploratory and correlated study, with a quantitative approach. It was made in sample with 42 nurses of a private, beneficent hospital oh an average category, in the city of São Paulo. The data had been gathered from February $28^{\text {th }}$ to march $2^{\text {nd }}$, 2002. The results point some failures in their communication, which are probably causing a negative impact on their subordinates. These failures point that there is a need of the leaders to make an effort to understand what is not verbally said by their subordinates, so that the leadership will be effective and the organization's goals.
\end{abstract}

\section{KEYWORDS}

Communication. Leadership. Interpersonal relations.

\author{
RESUMEN \\ Este trabajo busca verificar \\ como los enfermeros perciben \\ el proceso de comunicación \\ entre ellos y sus superiores. \\ Este estudio es de tipo \\ descriptivo, explorátorio, \\ correlacional, con abordaje \\ cuantitativa, fue realizado en \\ una muestra de 42 enfermeros \\ de un hospital privado, \\ beneficiente de porte medio \\ de la ciudad de San Pablo, \\ los datos fuerón colectados \\ en el período del 28/02 al \\ $02 / 03$ del 2002. Los resultados \\ indican que existen algunas \\ fallas en la comunicación de \\ los lideres que probablemente \\ este causando un impacto \\ negativo en sus liderados. \\ Estas fallas alertan la \\ necesidad de los lideres para \\ comprender lo que no es dicho \\ verbalmente por los liderados \\ para que la capacidad de \\ liderar sea efectiva y los \\ objetivos de la organización \\ concretizados.
}

\section{PALABRAS-CLAVE}

Comunicación. Liderazgo. Relaciones interpersonales.

\footnotetext{
1 Enfermeira de Educação Continuada do Hospital Santa Cruz 2 Professora LivreDocente do Depto de Enfermagem Médico Cirúrgico da Escola de Enfermagem da USP. Orientadora deste estudo. juliaps@usp.br
} 


\section{INTRODUÇÃO}

As instituições hospitalares têm exigido dos enfermeiros a habilidade de liderar. Certamente por meio de bons líderes haverá a formação de um grupo de pessoas comprometidas com a visão, missão e os objetivos de uma organização. Algumas organizações propõem cursos internos ou externos para que o enfermeiro faça uma reflexão sobre a importância de saber liderar e tenha recursos para praticar e aprimorar continuamente o exercício de liderança.

O Hospital Santa Cruz promoveu e arcou com todo o custo de um curso interno sobre gerenciamento administrativo e gestão de pessoas para todos os enfermeiros, almejando enfermeiros líderes capazes de obter dos liderados um trabalho em equipe que gere resultados quantitativos e qualitativos esperados ou por que não melhores. $\mathrm{O}$ curso apresentou os seguintes módulos: comunicação e marketing pessoal, gerenciamento administrativo e gestão de pessoas, excelência em serviço ao cliente e formação de equipe.

Entre os diversos setores de uma instituição hospitalar a área de Enfermagem é a que possui um maior número de funcionários. Por ser a área que tem o contato mais direto e contínuo com os clientes internos e externos, este fato justificou a aprovação de um curso interno direcionado para os enfermeiros.

A empresa acreditando que o desempenho organizacional depende daqueles que realizam e daqueles que supervisionam um trabalho, anualmente faz uma pesquisa de satisfação - e não identifica o setor para garantir o anonimato dos funcionários - com todos os seus os colaboradores, pois pessoas satisfeitas trabalham e produzem melhor. Cargos como diretores, gerentes, supervisores, supervisionam o trabalho de outras pessoas, tornando-se assim, responsáveis pelas atividades de uma equipe; fato que implica em liderança, e a liderança pressupõe um processo de comunicação para obtenção dos objetivos comuns de uma equipe.

\section{COMUNICAÇÃOEQUIPE E SUPERIORES}

Para alcançar os objetivos comuns é imprescindível que todos os componentes de um grupo tenham motivação. A motivação ocorre paralelamente à satisfação no trabalho ${ }^{(1)}$.
Ressaltando a importância das relações humanas na satisfação do trabalho, estas podem ser adquiridas na associação com os outros no trabalho e, um trabalho que tem sentido permite encontrar pessoas com quem os contatos podem ser francos, honestos, com quem se pode ter prazer em trabalhar mesmo em projetos difíceis. Um trabalho que não comporta nenhum interesse humano, em um meio ambiente onde as relações são superficiais, contribui para torná-lo absurdo ${ }^{(2)}$.

Pesquisa feita indica que os administradores passam cerca de $80 \%$ do seu dia de trabalho em comunicação direta com outras pessoas. Isto representa 48 minutos de cada hora gastos em reuniões, em conversas pessoais, ao telefone ou falando informalmente com outras pessoas. Os outros $20 \%$ do tempo do administrador são gastos em trabalhos escritos $^{(3)} .90 \%$ dos problemas das organizações giram em torno de uma comunicação imprópria, base dos principais conflitos que ocorrem dentro das organizações, sabotando decisões, ações e o alcance das metas organizacionais e individuais ${ }^{(4)}$.

Em uma organização, portanto, a comunicação é essencial para o exercício da influência, para a coordenação das atividades em grupo e para a efetivação do processo de liderança. Assim, o êxito do líder está relacionado com a sua habilidade de comunicar-se com outros ${ }^{(5)}$.

Uma comunicação adequada é difícil porque a maioria dos estímulos é transmitida por sinais e não por símbolos. As pessoas têm um conjunto próprio de idéias, valores, experiências, atribuindo a cada sinal um significado não só denotativo, mas principalmente conotativo ${ }^{(6)}$.

A comunicação é entendida aqui como um processo de compreender, compartilhar mensagens enviadas e recebidas, sendo que as próprias mensagens e o modo como ocorre o seu intercâmbio exercem influência no comportamento das pessoas nele envolvidas, a curto, médio ou longo prazo. Esta mudança pode ocorrer no ambiente em que a comunicação é efetuada ou quando as pessoas se encontram isoladas, distantes umas das outras ou do contexto. Isto permite afirmar que as pessoas se encontram constantemente envolvidas por um campo interacional ${ }^{(7)}$.

Cabe lembrarmos que a comunicação nãoverbal pode ser definida como sendo aquela que ocorre na interação de pessoa-a-pessoa, 
exceto as palavras por elas mesmas, é toda informação obtida por meio de gestos, posturas, expressões faciais, orientações do corpo, singularidades somáticas, naturais ou artificiais, organização dos objetos no espaço e até pela relação de distância mantida entre os indivíduos ${ }^{(6)}$. Depreende-se então, que a comunicação é mais efetiva quando as mensagens não-verbais também são reconhecidas e interpretadas adequadamente.

As funções da comunicação não-verbal são: expressar emoções, complementar ou reforçar o que está sendo dito verbalmente, substituir o verbal e contradizer o verbal ${ }^{(6)}$. Os sinais não-verbais emitidos e percebidos contribuem para gerar vínculos de confiança e confiamos em alguém, quando percebemos coerência e constância entre o que uma pessoa diz e faz, ou seja, um não-verbal complementar ao seu verbal; não contraditório ${ }^{(8)}$.

No futuro, os líderes aprenderão a ouvir, observar tendências e perceber as necessidades de outras pessoas ${ }^{(9)}$. O ouvir é a mais importante, a mais difícil e negligenciada das habilidades na comunicação. Ela requer que nos concentremos nos significados, nas palavras não ditas e nas expressões das pessoas. Atitude que ajudará o líder a compreender melhor a situação ${ }^{(4)}$.

\section{OBJETIVO DO TRABALHO}

Verificar como os enfermeiros de uma instituição estão percebendo o processo de comunicação entre eles e os superiores para a obtenção dos resultados estabelecidos pela organização.

\section{METODOLOGIA}

Tipo de estudo: $O$ estudo realizado foi do tipo descritivo, exploratório, correlacional, com abordagem quantitativa. Foi descritivo, pois apresentou sistematicamente as características do fenômeno em questão. Foi do tipo exploratório por buscar maiores informações sobre determinado assunto; correlacional por investigar o efeito de um fator sobre outro ou, outros fatores ${ }^{(10)}$. A abordagem foi quantitativa por procurar medir aspectos mais evidentes e observáveis do fenômeno.

Local e população do estudo: o estudo foi realizado em um hospital privado e beneficente de porte médio, da cidade de São Pau- lo, e a amostra, do tipo aleatória, foi constituída por $85.7 \%$ dos 42 enfermeiros dos diferentes setores do hospital. Não se adotou qualquer critério de elegibilidade.

Instrumento e procedimentos de coleta: após prévia autorização do Comitê de Ética e Pesquisa da instituição, em fevereiro de 2002, foi adotado um questionário contendo 16 perguntas estruturadas num esquema Likert que possibilita ótimas discriminações entre pessoas com ponto de vista diferentes (Anexo). Os questionários puderam ser respondidos fora do âmbito hospitalar, sendo devolvidos no dia seguinte. Os enfermeiros do estudo foram informados quanto ao objetivo do trabalho e aqueles que concordaram em participar assinaram o Termo de Consentimento Livre e Esclarecido, conforme decreto de 14/01/87; resolução CNS 196/96, sendo garantido o anonimato das respostas.

Este estudo trabalhou com as 16 questões propostas no instrumento, e tais questões foram divididas em Questões Relacionadas com a Chefia Geral (1, 9, 12 e 13); Questões Relacionadas com a Chefia Imediata (3, 4, 8, 10, 11 e 14); Questões Relacionadas com os Colegas (2, 5 e 7) e Questões Relacionadas com o Entendimento Próprio (6, 15 e 16). As variáveis foram mensuradas no nível ordinal. Exploratoriamente construímos um escore totalizador do resultado observado em cada grupo de questões e para tanto, inicialmente atribuímos escores de 1 a 5 conforme as respostas de discordo totalmente a concordo totalmente. Assim, a pontuação obtida em cada questionário passou a oscilar de 16 a 80. Usamos regra de três simples para padronizar a nota obtida. Quando o escore padronizado foi calculado sobre todas as 16 questões ele foi denominado Nota Global (NPGlobal), quando ele foi calculado para as questões relacionadas com a chefia geral ele foi denominado Nota para Chefia Geral (NCGeral), para a chefia imediata calculamos a Nota para Chefia Imediata (NCImed), para o pessoal calculamos a Nota para Pessoal (Npessoal) e para o entendimento pessoal, calculamos a Nota para o Entendimento Pessoal (NEP).

Análise de Dados: As análises Quantitativas do tipo Descritiva e Inferencial foram adotadas neste estudo. O primeiro tipo foi feito sobre todas as 16 variáveis do estudo e consistiu basicamente de distribuições de freqüências, cálculo de médias, desvios padrões, mínimo-máximo e de representação gráfica de Intervalos de Confiança para a Proporção
Comunicação entre líderes e liderados: visão dos enfermeiros 
Katia M.A.B. dos Santos Maria Júlia Paes da Silva
(Means plot). O segundo tipo foi levado a efeito através da análise de correlações ordinais entre as variáveis, e tal análise foi baseada no Coeficiente de Correlação Ordinal de Spearman e as correlações que apresentaram P-Value inferiores a 0,05 foram consideradas estatisticamente significativas $^{(11-12)}$.

\section{ANÁLISE DOS RESULTADOS}

\section{Caracterização das Respostas}

A Tabela 1 demonstra que para a questão 1 houve um predomínio de aprovações $(54,06 \%)$ seguido de abstenções (29,73\%) sugerindo aprovação dos esforços adotados pela diretoria do hospital para saber a opinião de seus funcionários. Para a questão 9, observamos predomínio de desaprovações (40,55\%) seguido de abstenções $(32,43 \%)$, sugerindo reprovação do processo de comunicação utilizado pelo hospital. Para a questão 12, predominaram aprovações $(72,98 \%)$, sugerindo aprovação do sistema de sinalização do hospital.
Para a questão 13, predominaram as desaprovações $(47,23 \%)$, sugerindo presença de problemas de comunicações com outras áreas. Quanto ao escore médio padronizado para a chefia geral, obtivemos média de 63,64 $(\mathrm{DP}=10.97)$ e variação de 40 a 80.

Há alguns pontos mais positivos e menos positivos na comunicação do hospital. A provável reprovação do processo de comunicação do hospital pelos enfermeiros deve ser valorizada, pois como referido na bibliografia, 90\% dos problemas das organizações são originadas de uma comunicação inadequada ${ }^{(4)}$.

A comunicação é um elemento importante no conceito de liderança para afetar o comportamento e o desempenho dos liderados a fim de realizar as metas estabelecidas por uma instituição. Cabe salientar que se os liderados não desempenham corretamente uma tarefa por falta de acesso a informação necessária, o líder falhou em seu papel de disseminador $^{(5)}$.

Tabela 1 - Distribuição das Respostas Ligadas à Chefia Geral. São Paulo, 2002

\begin{tabular}{|c|c|c|}
\hline \multirow{2}{*}{$\begin{array}{l}\text { VARIÁVEL } \\
\text { Questão } 1\end{array}$} & \multicolumn{2}{|c|}{ DISTRIBUIÇÃO } \\
\hline & $\mathbf{N}$ & $\%$ \\
\hline Discordo Totalmente & 1 & 2,70 \\
\hline Discordo & 5 & 13,51 \\
\hline Não Concordo nem Discordo & 11 & 29,73 \\
\hline Concordo & 17 & 45,95 \\
\hline Concordo Totalmente & 3 & 8,11 \\
\hline \multicolumn{3}{|l|}{ Questão 9} \\
\hline Discordo Totalmente & 2 & 5,41 \\
\hline Discordo & 13 & 35,14 \\
\hline Não Concordo nem Discordo & 12 & 32,43 \\
\hline Concordo & 9 & 24,32 \\
\hline Concordo Totalmente & 1 & 2,70 \\
\hline \multicolumn{3}{|l|}{ Questão 12} \\
\hline Discordo Totalmente & 1 & 2,70 \\
\hline Discordo & 4 & 10,81 \\
\hline Não Concordo nem Discordo & 5 & 13,51 \\
\hline Concordo & 25 & 67,57 \\
\hline Concordo Totalmente & 2 & 5,41 \\
\hline \multicolumn{3}{|l|}{ Questão 13} \\
\hline Discordo Totalmente & 2 & 5,56 \\
\hline Discordo & 15 & 41,67 \\
\hline Não Concordo nem Discordo & 7 & 19,44 \\
\hline Concordo & 8 & 22,22 \\
\hline Concordo Totalmente & 4 & 11,11 \\
\hline
\end{tabular}


A Figura 1 sugere não haver diferença estatisticamente significativa nas proporções de concordâncias entre as questões 1 e 12 (A diretoria do Hospital se esforça em saber a opinião e o pensamento dos colaboradores; e $\mathrm{O}$ sistema de sinalização do Hospital é claro, permitindo fácil locomoção e localização entre os setores) e entre as questões 9 e 13 (O processo de comunicação do Hospital é eficiente, eficaz, aberto e claro; e Os problemas de comunicação com outras áreas têm afetado meu desempenho profissional), todavia sugere que as primeiras porcentagens (de 1 e 12) superam as segundas proporções (de 9 e 13).

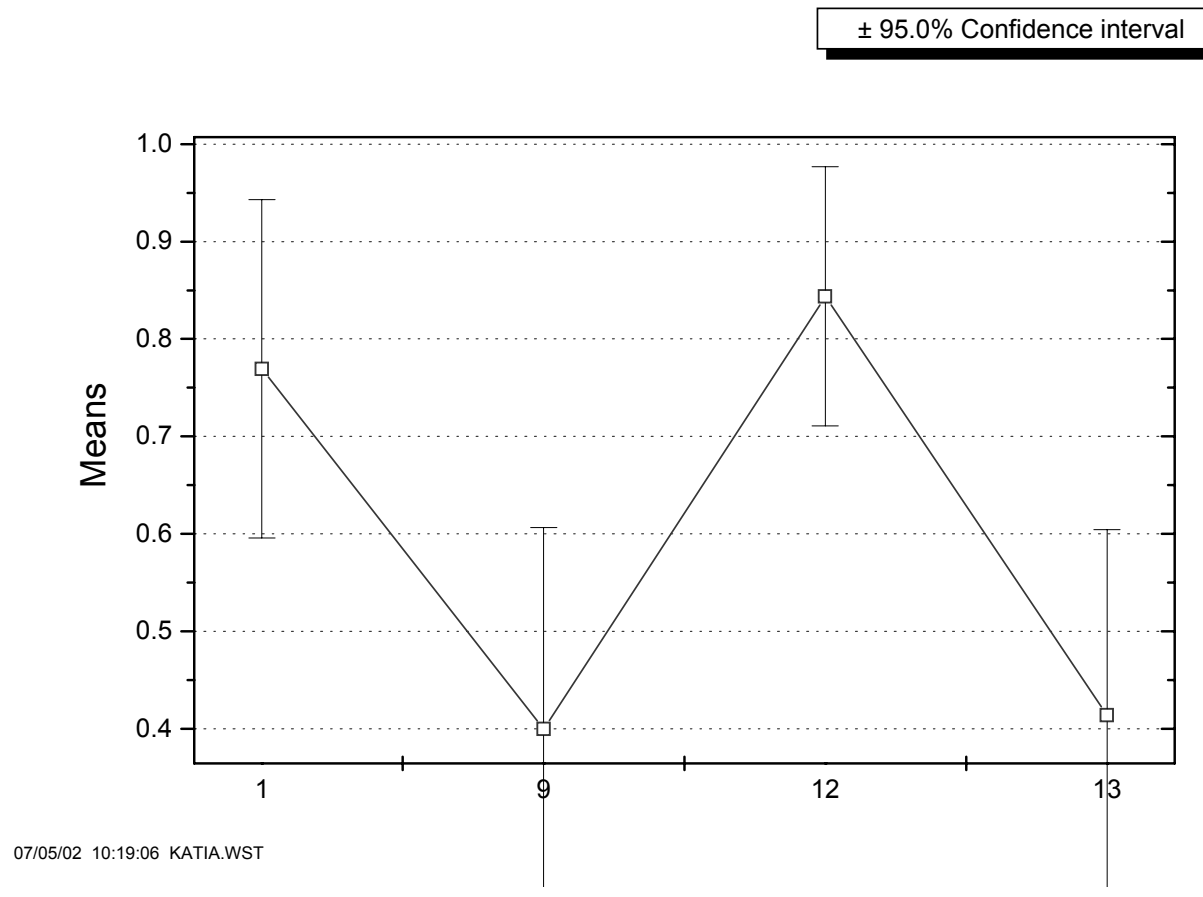

Figura 1 - Means plot para a proporção média de concordâncias nas questões 1, 9, 12 e 13.

A Tabela 2 demonstra que para a questão 3 houve um predomínio de desaprovações (48,65\%) seguido de abstenções $(27,03 \%)$ sugerindo ausência de recebimento de elogios do superior direto aos enfermeiros. Para a questão 4, observamos empate entre desaprovações e abstenções $(35,14 \%)$, sugerindo que não há crítica construtiva ao desempenho/trabalho dos enfermeiros. Para a questão 8, observamos abstenções (40,54\%) e empate entre aprovações e desaprovações (29,73\%), sugerindo que as opiniões dos enfermeiros não são tão aceitas de maneira acolhedora. Para a questão 10 , observamos um predomínio de aprovações (45,95\%), seguido de abstenções $(35,14 \%)$ sugerindo que o superior imediato mantém um relacionamento claro, direto e constante com seus colaboradores. Para a questão 11 observamos um predomínio das aprovações $(62,16 \%)$, sugerindo que o superior imediato fornece oportunidade ao enfermeiro de dar opiniões e de exercer um trabalho estimulante e interessante. Para a questão 14 observamos um predomínio de aprovações $(48,65 \%)$, se- guido de abstenções (32,43\%), sugerindo que o superior não demonstra favoritismo por determinados colaboradores. Quanto ao escore médio padronizado para a chefia imediata, obtivemos média de $61,53(\mathrm{DP}=14.37)$ variação de 26,67 a 83,33 .

A possível ausência de recebimento de elogios, a falta de crítica construtiva ao desempenho, a não aceitação total das opiniões dos enfermeiros pela chefia imediata podem estar propiciando insatisfação na realização do trabalho. Para que um trabalho seja satisfatório para quem o realiza, parece ser importante que ele apele para suas competências ${ }^{(2)}$. Além disso, parece relevante que o trabalhador tenha a oportunidade de testar suas capacidades, com o objetivo de estimular suas necessidades de crescimento pessoal e seu senso de responsabilidade. Isso é oferecido por uma organização que deixa os empregados serem os administradores de suas atividades e que, por meio da presença de mecanismos de feedback, lhes mantém
Comunicação entre líderes e liderados: visão dos enfermeiros 
Katia M.A.B. dos Santos Maria Júlia Paes da Silva informados sobre a evolução do seu desempenho e lhes permite fazer os ajustes necessários para melhorá-lo e assim alcançar os resultados previstos pela organização.

Há evidência de que o superior imediato fornece oportunidade ao enfermeiro de dar opiniões e de exercer um trabalho estimulante e interessante, porém, qualquer plano estratégico, fica adormecido sem a presença de um líder que contribua com a motivação e guie as pessoas em busca das metas ${ }^{5}$. Assim podemos afirmar que a maneira de comunicar e a coerência entre o discurso e a prática de um líder são fundamentais para obtenção dos resultados esperados.

As aprovações que indicam que o superior imediato mantém um relacionamento claro, direto e constante com seus colaboradores, podem estar relacionadas com uma liderança autoritariamente clara, se considerarmos as prováveis reprovações dos enfermeiros. Liderança que pode estar funcionando na base do poder de recompensas, do poder da coerção, baseada exclusivamente no poder da posição que a organização confere ao líder ${ }^{(4)}$.

Tabela 2 - Distribuição das questões relacionadas à chefia imediata. São Paulo, 2002.

\begin{tabular}{|c|c|c|}
\hline \multirow{2}{*}{$\begin{array}{l}\text { VARIÁVEL } \\
\text { Questão } 3\end{array}$} & \multicolumn{2}{|c|}{ DISTRIBUIÇÃO } \\
\hline & $\mathbf{N}$ & $\%$ \\
\hline $\begin{array}{l}\text { Discordo Totalmente } \\
\text { Discordo } \\
\text { Não Concordo nem Discordo } \\
\text { Concordo } \\
\text { Concordo Totalmente }\end{array}$ & $\begin{array}{r}3 \\
15 \\
10 \\
9 \\
0\end{array}$ & $\begin{array}{r}8,11 \\
40,54 \\
27,03 \\
24,32 \\
0,00\end{array}$ \\
\hline \multicolumn{3}{|l|}{ Questão 4} \\
\hline $\begin{array}{l}\text { Discordo Totalmente } \\
\text { Discordo } \\
\text { Não Concordo nem Discordo } \\
\text { Concordo } \\
\text { Concordo Totalmente }\end{array}$ & $\begin{array}{c}3 \\
10 \\
13 \\
11 \\
0\end{array}$ & $\begin{array}{r}8,11 \\
27,03 \\
35,14 \\
29,73 \\
0,00\end{array}$ \\
\hline \multicolumn{3}{|l|}{ Questão 8} \\
\hline $\begin{array}{l}\text { Discordo Totalmente } \\
\text { Discordo } \\
\text { Não Concordo nem Discordo } \\
\text { Concordo } \\
\text { Concordo Totalmente }\end{array}$ & $\begin{array}{r}0 \\
11 \\
15 \\
11 \\
0\end{array}$ & $\begin{array}{r}0,00 \\
29,73 \\
40,54 \\
29,73 \\
0,00\end{array}$ \\
\hline \multicolumn{3}{|l|}{ Questão 10} \\
\hline $\begin{array}{l}\text { Discordo Totalmente } \\
\text { Discordo } \\
\text { Não Concordo nem Discordo } \\
\text { Concordo } \\
\text { Concordo Totalmente }\end{array}$ & $\begin{array}{c}1 \\
6 \\
13 \\
15 \\
2\end{array}$ & $\begin{array}{r}2,70 \\
16,22 \\
35,14 \\
40,54 \\
5,41\end{array}$ \\
\hline \multicolumn{3}{|l|}{ Questão 11} \\
\hline $\begin{array}{l}\text { Discordo Totalmente } \\
\text { Discordo } \\
\text { Não Concordo nem Discordo } \\
\text { Concordo } \\
\text { Concordo Totalmente }\end{array}$ & $\begin{array}{c}3 \\
6 \\
5 \\
20 \\
3\end{array}$ & $\begin{array}{r}8,11 \\
16,22 \\
13,51 \\
54,05 \\
8,11\end{array}$ \\
\hline \multicolumn{3}{|l|}{ Questão 14} \\
\hline $\begin{array}{l}\text { Discordo Totalmente } \\
\text { Discordo } \\
\text { Não Concordo nem Discordo } \\
\text { Concordo } \\
\text { Concordo Totalmente }\end{array}$ & $\begin{array}{c}2 \\
5 \\
12 \\
18 \\
0\end{array}$ & $\begin{array}{r}5,41 \\
13,51 \\
32,43 \\
48,65 \\
0,00\end{array}$ \\
\hline
\end{tabular}


O exame da Figura 2 sugere não haver diferença estatisticamente significativa nas proporções de concordância entre as questões 3, 4 e 8 (Costumo receber elogios do superior; Recebo críticas construtivas com relação ao meu desempenho; e Em minha área, as opiniões são aceitas de maneira acolhedora) e entre as ques- tões 10, 11 e 14 (Meu superior imediato mantém um relacionamento claro, direto e constante com seus colaboradores; Meu superior imediato me fornece oportunidade de dar opiniões e de exercer um trabalho estimulante e interessante; Meu superior não demonstra favoritismo por determinados colaboradores).

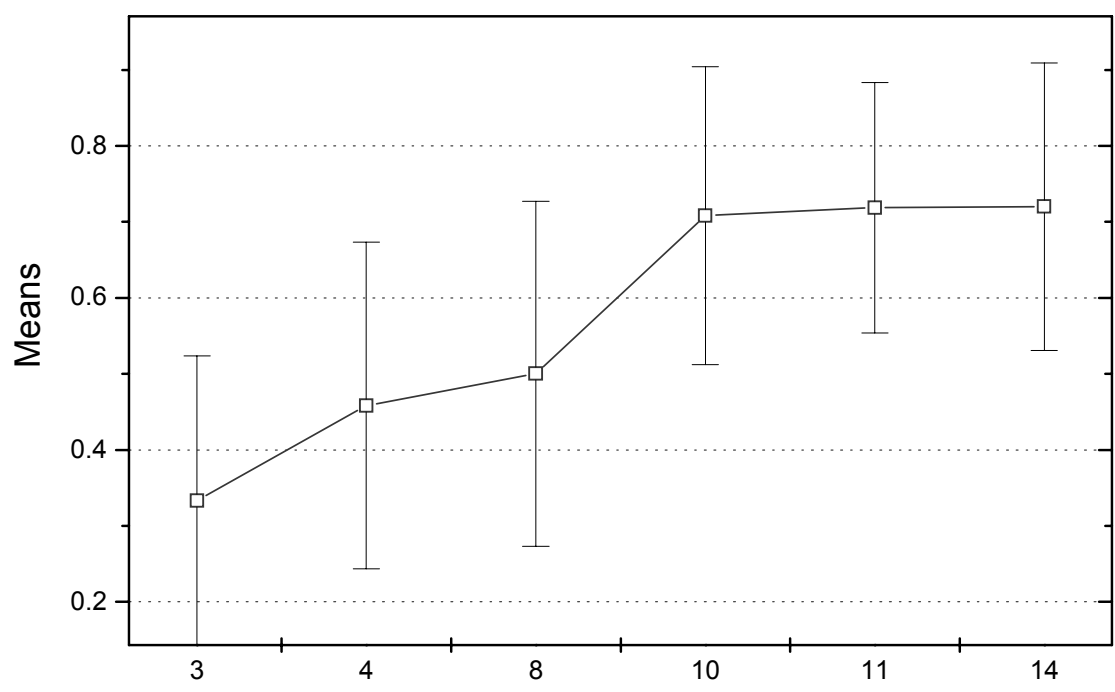

07/05/02 10:21:33 KATIA.WST

Figura 2 - Means plot para a proporção média de concordâncias nas questões 3 , $4,8,10,11$ e 14

A Tabela 3 demonstra que para a questão 2 houve um predomínio de aprovações (48,65\%) seguido de abstenções (29,73\%) sugerindo que as pessoas com as quais os enfermeiros convivem são alegres e bem humoradas. Para a questão 5, observamos desaprovações $(37,84 \%)$ seguido de aprovações $(32,43 \%)$, sugerindo que as pessoas não falam de forma honesta e aberta. Para a questão 7, observamos aprovações $(43,24 \%)$, seguido de abstenções $(37,84 \%)$ sugerindo que existe cooperação entre os grupos de trabalho na área de enfermagem. Quanto ao escore médio padronizado para os colegas, obtivemos média de 61,62 (DP=13.27) e variação de 26.67 a 80 .
A probabilidade das pessoas não falarem de forma honesta e franca pode estar proporcionando um trabalho onde as relações são superficiais. Vários administradores reportaram que um trabalho que tem sentido permite encontrar pessoas com quem os contatos podem ser francos e honestos ${ }^{(2)}$.

O fato das pessoas não se expressarem franca e honestamente, também pode ser decorrente de um sistema administrativo marcado pela rigidez hierárquica e pelos métodos tradicionais de organização de trabalho, onde o líder obterá poucas informações no desempenho de seu papel de monitor ${ }^{(5)}$.
Comunicação entre líderes e liderados: visão dos enfermeiros 
Katia M.A.B. dos Santos Maria Júlia Paes da Silva
Tabela 3 - Distribuição das questões relacionadas com os colegas. São Paulo, 2002

\begin{tabular}{lcr}
\hline VARIÁVEL & \multicolumn{2}{c}{ DISTRIBUIÇÃO } \\
\hline Questão 2 & 0 & $\%$ \\
\hline Discordo Totalmente & 8 & 21,62 \\
Discordo & 11 & 29,73 \\
Não Concordo nem Discordo & 18 & 48,65 \\
Concordo & 0 & 0,00 \\
Concordo Totalmente & & \\
\hline Questão 5 & 3 & 8,11 \\
\hline Discordo Totalmente & 11 & 29,73 \\
Discordo & 10 & 27,03 \\
Não Concordo nem Discordo & 12 & 32,43 \\
Concordo & 0 & 0,00 \\
Concordo Totalmente & & 5,41 \\
\hline Questão 7 & 2 & 13,51 \\
\hline Discordo Totalmente & 5 & 37,84 \\
Discordo & 14 & 43,24 \\
Não Concordo nem Discordo & 16 & 0,00 \\
Concordo & 0 & \\
Concordo Totalmente & & \\
\hline
\end{tabular}

O exame da Figura 3 sugere não haver diferença estatisticamente significativa nas proporções de concordância das questões 2 e 7 (As pessoas com as quais convivo são alegres e bem humoradas; e Há cooperação en-

tre os grupos de trabalho de minha área), sugerindo também que tais proporções superam a proporção de concordância da questão 5 (As pessoas de minha área falam de forma honesta e aberta).

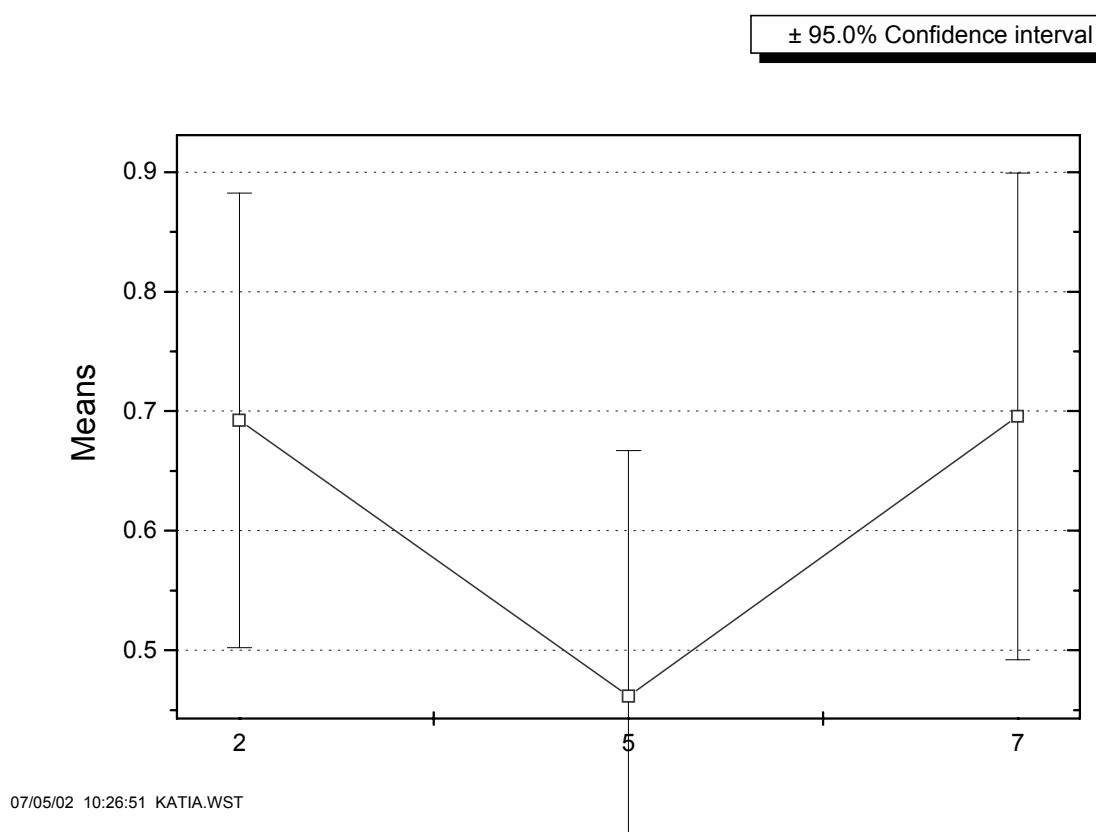

Figura 3 - Means plot para a proporção média de concordâncias nas questões 2, 5 e 7 
A Tabela 4 demonstra que para a questão 6 houve um predomínio de aprovações $(54,05 \%)$ seguido de desaprovações $(24,33 \%)$ sugerindo que os enfermeiros entendem como seu desempenho é avaliado. Para a questão 15 , observamos predomínio de desaprovações $(35,13 \%)$ seguido de empate entre abstenções e aprovações $(32,43 \%)$, sugerindo que os enfermeiros não sentem reconhecimento pelo seu trabalho. Para a questão 16 , predominaram aprovações $(43,24)$, seguido de abstenções $(32,43 \%)$, sugerindo que os enfermeiros se sentem respeitados e realizados na empresa. Quanto ao escore médio padronizado para o entendimento próprio, obtivemos média de 62.16(DP $=16.18)$ e variação de 26.67 a 86.67 .

A comunicação eficiente provoca mudanças esperadas no comportamento dos indivíduos, através do desenvolvimento de atitudes positivas em relação ao próprio desempenho, que culmina com a satisfação profissional $^{(5)}$.

Analisando o provável não reconhecimento do trabalho dos enfermeiros e o fato destes entenderem como seu desempenho é avaliado, pode-se inferir que não está havendo um entendimento comum, ou seja, o enfermeiro não está sendo ouvido, podendo causar-lhe insatisfação pessoal e profissional.

Em relação ao respeito e a realização na empresa pode ser que estes valores sejam sentidos entre os enfermeiros e pacientes, o que não ocorre com a chefia, já que há evidências de não reconhecimento do trabalho, falta de elogios, aceitação das opiniões e reconhecimento do trabalho dos enfermeiros.

Tabela 4-Distribuição das questões relacionadas com o entendimento próprio. São Paulo, 2002

\begin{tabular}{lcc}
\hline VARIÁVEL & \multicolumn{2}{c}{ DISTRIBUIÇÃO } \\
\hline Questão 6 & N & \% \\
\hline Discordo Totalmente & 2 & 5,41 \\
Discordo & 7 & 18,92 \\
Não Concordo nem Discordo & 8 & 21,62 \\
Concordo & 19 & 51,35 \\
Concordo Totalmente & 1 & 2,70 \\
\hline Questão 15 & & \\
\hline Discordo Totalmente & 1 & 2,70 \\
Discordo & 12 & 32,43 \\
Não Concordo nem Discordo & 12 & 32,43 \\
Concordo & 12 & 32,43 \\
Concordo Totalmente & 0 & 0,00 \\
\hline Questão 16 & & \\
\hline Discordo Totalmente & 4 & 10,81 \\
Discordo & 5 & 13,51 \\
Não Concordo nem Discordo & 12 & 32,43 \\
Concordo & 15 & 40,54 \\
Concordo Totalmente & 1 & 2,70 \\
\hline
\end{tabular}

O exame da Figura 4 sugere não haver diferença estatisticamente significativa nas proporções de concordância das questões 6,15 e 16 (Entendo como meu desempenho éavaliado; Sou reconhecido quando faço um bom trabalho; e Sinto-me respeitado e realizado na Empresa). 
Katia M.A.B. dos Santos Maria Júlia Paes da Silva

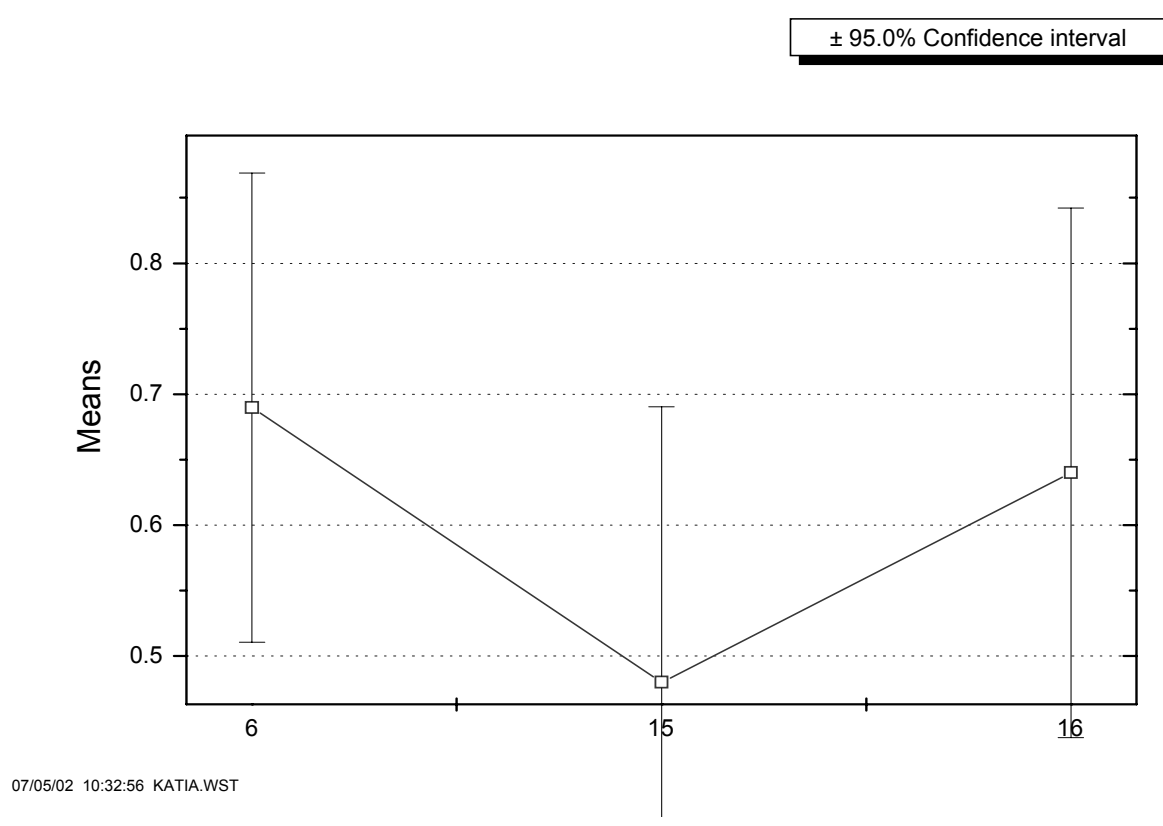

Figura 4 - Means plot para a proporção média de concordâncias entre as questões 6, 15 e 16.

\section{CORRELAÇÕES}

O exame da Tabela 5 sugere correlação positiva estatisticamente significativa entre NCGeral e NCImed, NEP e NP Global; o mesmo entre a variável NCImed e Npessoal, NEP e NPGlobal; entre a variável Npessoal e NEP e NPGlobal, e entre NEP e NPGlobal. Em síntese, altos escores atribuídos a um dos quesitos tende a estar associado a altos escores para os demais (em cadeia).
A correlação entre as variáveis indica que todas as relações interpessoais de uma instituição envolvem líderes e liderados, e se os líderes causam um profundo impacto na vida das pessoas e das organizações, estes devem estar atentos ao processo de comunicação para que sua liderança exerça uma influência interpessoal intencional que também possa modificar ou provocar o comportamento de uma outra pessoa para a consecução dos objetivos propostos ${ }^{(4)}$.

Tabela 5 - Correlação ordinal entre as Notas Atribuídas. São Paulo, 2002

\begin{tabular}{cccccc}
\hline & NCGeral & NCImed & Npessoal & NEP & NP Global \\
\hline NCGeral & 1.00 & & & & \\
NCImed & $0.57^{*}$ & 1.00 & & & \\
Npessoal & 0.21 & $0.63^{*}$ & 1.00 & & \\
NEP & $0.37^{*}$ & $0.79^{*}$ & $0.56^{*}$ & 100 & \\
NP Global & $0.67^{*}$ & $0.94^{*}$ & $0.68^{*}$ & $0.86^{*}$ & 1.00 \\
\hline
\end{tabular}

\section{CONCLUSÕES}

Este estudo mostrou que os enfermeiros reprovam alguns aspectos no processo de comunicação entre eles e seus superiores. Reprovações que implicam na necessidade de uma revisão na forma como está ocorrendo a comunicação entre os profissionais de Enfermagem. A análise e solução de tais pro- blemas percebidos pelos enfermeiros na relação interpessoal possibilitará, e muito, o alcance dos resultados estabelecidos pela organização. As reprovações no processo de comunicação percebidas pelos enfermeiros foram: problemas no processo de comunicação utilizado pelo hospital, problemas de comunicação com outras áreas, ausência de elogios do superior direto aos enfermeiros, au- 
sência de críticas construtivas do desempenho profissional dos enfermeiros, o não acolhimento das opiniões dos enfermeiros, pessoas que não falam de forma honesta e aberta e o não reconhecimento do trabalho do enfermeiro.

Estas reprovações indicam que algumas falhas na comunicação dos líderes está causando impacto negativo em seus liderados.
Aspectos que alertam para a necessidade dos líderes realizarem um esforço para compreender o que não é dito verbalmente pelos liderados, para que a liderança seja efetiva e os objetivos de uma organização concretizados.

No futuro, os líderes aprenderão a ouvir, observar tendências e perceber as necessidades de outras pessoas ${ }^{(9)}$.
Comunicação entre líderes e liderados: visão dos enfermeiros

\section{REFERÊNCIAS}

(1) Andrade TGCS, Yokota O, Gomi IK, Lima $\mathrm{SM}$, Sakamoto EM. O enfermeiro e sua percepção sobre liderança em enfermagem. In: Anais do $2^{\circ}$ Simpósio Brasileiro de Comunicação em Enfermagem. 1990 mai 02-04. Ribeirão Preto. Ribeirão Preto; Escola de Enfermagem de Ribeirão Preto/USP; 1988. p.249-70.

(2) Morin EM. Os sentidos do trabalho. Rev Adm Empres; 2001. 41:8-19.

(3) Chiavenato I. Administração nos novos tempos. São Paulo: Makron Books; 1999. Comunicação e negociação nas organizações; cap.15, p.515-51.

(4) Chiavenato I. Administração nos novos tempos. São Paulo: Makron Books; 1999. Liderança nas organizações; cap.16, p.535-88.

(5) Trevizan MA, Mendes IAC. O líder como fonte central de comunicação. In: Anais do Simpósio Brasileiro de Comunicação em Enfermagem. 1988 mai 02-04; Ribeirão Preto. Ribeirão Preto. Escola de Enfermagem de Ribeirão Preto/USP; 1988. p. 297-307.
(6) Silva MJP.Comunicação tem remédio a comunicação nas relações interpessoais em saúde. 2 ed. São Paulo: Gente,1996.

(7) Stefanelli, MC. Comunicação com paciente teoria e ensino. 2ed. São Paulo: Robe, 1993.

(8) Silva MJP. Percebendo o ser humano além da doença - o não-verbal detectado pelo enfermeiro. Nursing (São Paulo) 2001; 41:14-20.

(9) Lopes Neto D. Liderança transformacional: a arte de administrar com inteligência emocional. Nursing (São Paulo) 2000; 21:16-18.

(10) Martins GA. Manual para elaboração de monografias e dissertações.São Paulo: Atlas, 1994.

(11) Bailar JC, Mosteller F. Medical users of statistics. $2^{a}$ edition. Boston, Massachusetts: Nejm Books, 1992.

(12) Berquó ES, Souza JMP, Gotlieb SLD. Bioestatística. São Paulo: EPU; 1981. 


\section{ANEXO \\ QUESTIONÁRIO}

\begin{tabular}{|c|c|c|c|c|c|c|}
\hline & & $\begin{array}{l}\text { CON- } \\
\text { CORDO } \\
\text { TOTAL } \\
\text { MENT }\end{array}$ & $\begin{array}{l}\text { CON- } \\
\text { CORDO }\end{array}$ & $\begin{array}{c}\text { NÃO } \\
\text { CON- } \\
\text { CORDO } \\
\text { NEM } \\
\text { DIS- } \\
\text { CORDO }\end{array}$ & $\begin{array}{l}\text { DIS- } \\
\text { CORDO }\end{array}$ & $\begin{array}{l}\text { DIS- } \\
\text { CORDO } \\
\text { TOTAL } \\
\text { MENT }\end{array}$ \\
\hline 1 & $\begin{array}{l}\text { A diretoria do Hospital se esforça em } \\
\text { saber a opinião e o pensamento dos } \\
\text { colaboradores }\end{array}$ & & & & & \\
\hline 2 & $\begin{array}{l}\text { As pessoas com as quais convivo são } \\
\text { alegres e bem humoradas }\end{array}$ & & & & & \\
\hline 3 & $\begin{array}{l}\text { Costumo receber elogios do meu } \\
\text { superior imediato quando faço um } \\
\text { bom trabalho }\end{array}$ & & & & & \\
\hline 4 & $\begin{array}{l}\text { Em geral recebo crítica construtiva } \\
\text { com relação ao meu desempenho / } \\
\text { trabalho }\end{array}$ & & & & & \\
\hline 5 & $\begin{array}{l}\text { As pessoas da minha área, falam de } \\
\text { forma honesta e aberta }\end{array}$ & & & & & \\
\hline 6 & $\begin{array}{l}\text { Entendo como meu desempenho é } \\
\text { avaliado }\end{array}$ & & & & & \\
\hline 7 & $\begin{array}{l}\text { Existe constante cooperação entre os } \\
\text { grupos de trabalho de minha área }\end{array}$ & & & & & \\
\hline 8 & $\begin{array}{l}\text { Em minha área, as opiniões são } \\
\text { aceitas de maneira acolhedora }\end{array}$ & & & & & \\
\hline 9 & $\begin{array}{l}\text { O processo de comunicação utilizado } \\
\text { pelo Hospital é eficiente, eficaz, } \\
\text { aberto e claro }\end{array}$ & & & & & \\
\hline 10 & $\begin{array}{l}\text { Meu superior imediato mantém um } \\
\text { relacionamento claro, direto e } \\
\text { constante com seus colaboradores }\end{array}$ & & & & & \\
\hline 11 & $\begin{array}{l}\text { Meu superior imediato me fornece } \\
\text { oportunidade de dar opiniões e de } \\
\text { exercer um trabalho estimulante e } \\
\text { interessante }\end{array}$ & & & & & \\
\hline 12 & $\begin{array}{l}\text { O sistema de sinalização no Hospital } \\
\text { é claro; permitindo fácil locomoção e } \\
\text { localização dos setores }\end{array}$ & & & & & \\
\hline 13 & $\begin{array}{l}\text { Os problemas de comunicação com } \\
\text { outras áreas têm afetado meu } \\
\text { desempenho profissional }\end{array}$ & & & & & \\
\hline 14 & $\begin{array}{l}\text { Meu superior imediato não } \\
\text { demonstra favoritismo por } \\
\text { determinados colaboradores }\end{array}$ & & & & & \\
\hline 15 & $\begin{array}{l}\text { Sou reconhecido quando faço um bom } \\
\text { trabalho }\end{array}$ & & & & & \\
\hline 16 & $\begin{array}{l}\text { Sinto-me respeitado e realizado na } \\
\text { empresa }\end{array}$ & & & & & \\
\hline
\end{tabular}

